\title{
Las relaciones de Bolivia y Chile en la actualidad: una agenda más allá de las disputas*
}

\section{Relations between Bolivia and Chile today: an agenda beyond disputes}

\author{
Natalia Ceppi \\ Consejo Nacional de Investigaciones Científicas y Técnicas (CONICET), Argentina \\ Universidad Nacional de Rosario, Argentina
}

Autor para correspondencia: nataliaceppi@yahoo.com.ar

Fecha de recepción: 26 de Mayo de 2017 - Fecha de aceptación: 15 de Septiembre de 2017

\section{Resumen}

El presente trabajo se propone analizar los principales temas que son parte de los contactos entre Bolivia y Chile en la actualidad. En este sentido, se reflexiona, en primer lugar, sobre los diferendos que ambos Estados mantienen en la Corte Internacional de Justicia (CIJ): la cuestión marítima y las aguas del Silala. Ambas temáticas, en especial, el reclamo boliviano por obtener una salida soberana al Pacífico, constituyen issue areas sensibles en el vínculo entre los dos países al involucrar cuestiones relacionadas con la soberanía. En segundo lugar, se examinan los aspectos más destacados de otros ejes que también son parte de la agenda bilateral, tales como la dimensión comercial; la cooperación técnica y la migración transfronteriza. Éstos, a pesar de contar con una trascendencia menor en la agenda compartida, le ofrecen la posibilidad a ambas Cancillerías de trabajar en espacios de consenso y colaboración.

Palabras clave: Bolivia-Chile; relaciones bilaterales; agenda histórica; conflicto; cooperación

\begin{abstract}
This paper analyzes the main issues that are part of the relation between Bolivia and Chile in the present century. The article invites to reflect about, in first place, the cases in the International Court of Justice (ICJ): the marine dispute and the waters of the Silala. Both subjects are very sensitive in the bilateral agenda especially; the bolivian claim to negotiate the access to the Pacific Ocean because involves a conflictive past related to sovereignty. Secondly, other issues are examined, such as bilateral trade; technical cooperation and cross-border migration. These have a relative impact in the bilateral contacts but offer the possibility for the Departments of Foreign Affairs to work in spaces of consensus and cooperation.
\end{abstract}

Key words: Bolivia-Chile; bilateral relations; historical agenda; conflict; cooperation

\footnotetext{
* Unas líneas preliminares de esta investigación fueron esbozadas en el XII Congreso Chileno de Ciencia Política, Chile (octubre, 2016).
} 


\section{Introducción}

Desde la firma del Tratado de Paz y Amistad en 1904, las relaciones boliviano-chilenas han transitado por situaciones de enemistad, tirantez, indiferencia y hasta un breve período de acercamiento durante la primera presidencia de Michelle Bachelet (2006-2010), generando la existencia de un vínculo complejo, intrincado y en ocasiones, caótico. El sostenimiento de la demanda de Bolivia de obtener una salida soberana al mar - perdida tras la Guerra del Pacífico- y la desestimación de Chile de avanzar sobre una cuestión que forma parte de la 'agenda histórica', ha favorecido la construcción de una lógica relacional de alteridad negativa que encapsuló el vínculo en la desconfianza y la existencia de posturas que, por lo menos al presente, son inamovibles.

Las relaciones diplomáticas fueron interrumpidas en 1978 y durante décadas, los dos países han mantenido posiciones antagónicas donde conviven los discursos nacionalistas, la demonización del otro y la negación de derechos (Lacoste, 2015). Todo ello, ha entorpecido la disposición al diálogo, siendo la muestra más elocuente la judicialización de aquellas temáticas que poseen relevancia en las políticas estatales, a saber, la demanda boliviana de negociar un acceso soberano al Pacífico y más recientemente la disputa en torno a las aguas del Silala; ambas presentadas ante la Corte Internacional de Justicia (CIJ).

Sin duda, la centralización y/o reducción de la agenda bilateral al tratamiento de los diferendos, con especial énfasis a la cuestión marítima, ha sido un obstáculo para potenciar otras issue areas que son entendidas como tradicionales en los contactos entre dos vecinos, tales como el comercio, las amenazas transnacionales, las dinámicas migratorias, las problemáticas medioambientales y los lineamientos de cooperación, entre otros. Es decir, a pesar de las disputas mencionadas, entre ambos países se identifican espacios de interacción en los cuales se han desarrollado iniciativas en base a los intereses comunes, cuyos avances y retrocesos responden a factores coyunturales diversos (Correa Vera \& García Pinzón, 2012: 83).

De acuerdo con lo mencionado, el presente trabajo propone reflexionar no sólo sobre los ejes más importantes de las demandas que Bolivia y Chile han llevado ante La Haya -las problemáticas más álgidas de la relación- sino también sobre otros temas que integran la agenda compartida y cuyo fortalecimiento podría contribuir en otorgarle otro matiz a la vinculación y encauzarla paulatinamente a un mayor acercamiento en estas cuestiones.

Estas líneas de investigación se encuentran organizadas en dos secciones. La primera, recorre desde una perspectiva general, los diferendos que Bolivia y Chile sostienen ante La Haya con el objetivo de realizar un balance de ambas posiciones nacionales. En la segunda sección se analizan los aspectos más destacados de tres temáticas de la agenda bilateral: comercio; cooperación técnica horizontal y dinámica migratoria transfronteriza. Éstas, entre otras, ofrecen la posibilidad de consenso en una vinculación atravesada por las tensiones y la desconfianza.

\section{La demanda marítima y las aguas del Silala ante la CIJ}

La ruptura de relaciones diplomáticas en 1978 coadyuvó a fortalecer la inestabilidad política del vínculo, siendo más cercano al resurgimiento de enfrentamientos que a las posibilidades de cooperación. Durante la década del noventa, la convergencia de regímenes 
democráticos y modelos de desarrollo neoliberales fue considerada, en un primer momento, como una oportunidad para focalizar la relación en las coincidencias (Rosales, 2011) No obstante, "este contexto no fue garantía en el proceso de estabilización de un [vínculo] bilateral altamente conflictivo" ni pudo mitigar el peso de la agenda histórica (Rosales, 2011: 83).

Años más tarde, esa sensación de oportunidad volvió a percibirse con los gobiernos de Evo Morales y Michelle Bachelet tras el lanzamiento de la Agenda de los Trece Puntos -también denominada agenda sin exclusiones- en la cual se incorporó el tratamiento de la cuestión marítima (punto VI) y las aguas del Silala (punto VII). Esta instancia evidenciaba una predisposición al diálogo con el objetivo de encontrar mecanismos de superación de las diferencias existentes entre los dos Estados y mejorar la calidad del vínculo bilateral (Correa Vera \& García Pinzón, 2013; Lorenzini, 2017).

Durante el primer mandato de Bachelet (2006-2010), las reuniones del Mecanismo de Consultas Políticas Bolivia-Chile se llevaron adelante sin ningún inconveniente (Cuadro I). Sin embargo, para Bolivia, los resultados no fueron los esperados ya que ese diálogo que fue sostenido no arrojó soluciones prácticas para abordar ni el reclamo de acceso soberano al Pacífico ni el aprovechamiento de las aguas del Silala.

A partir de la llegada de Sebastián Piñera (2010-2014), la Agenda de los Trece Puntos comenzó a perder relevancia como instrumento de conexión política porque su sustento, es decir, las conversaciones bilaterales fueron suspendidas y cada gobierno responsabilizó a su homólogo de lo sucedido. Con respecto al tema marítimo, es interesante considerar las reflexiones de Coloma Rojas (2012: 142), quien destaca que, como la soberanía se encontraba fuera de discusión para Chile, en realidad, el punto VI de la agenda sin exclusiones "nunca tuvo el mismo nivel de importancia para los dos interlocutores". Frente a esto podría inferirse que las administraciones de Morales y Bachelet mostraron inclinación al diálogo pero no existió voluntad de moverse de las posiciones sostenidas. Mientras que para Chile la negativa de otorgar un acceso soberano al mar no estaba en discusión, para Bolivia la condición de 'soberano' constituía un derecho irrenunciable. En 2011, el Presidente Morales decretó la creación de la Dirección Estratégica de Reivindicación Marítima (DIREMAR); organismo que sería el encargado de preparar la demanda boliviana ante La Haya.

\begin{tabular}{cc}
\hline Fecha & Resolución \\
\hline $19 / 10 / 2007$ & Tema marítimo: Acordaron la necesidad de mantener el diálogo bilateral desde una \\
& perspectiva constructiva. \\
& Silala: Llamaron a la reunión del Grupo de Trabajo sobre la temática. \\
\hline $21 / 11 / 2008$ & Tema marítimo: Los gobiernos destacaron el mantenimiento del diálogo bilateral. Este \\
& último forma parte de un proceso de construcción de confianza entre los dos países. \\
& Silala: Se celebró la aprobación (14/10/2008) del Programa de Estudios Técnicos a ser \\
& ejecutado de 4 a 5 años. Se avanzó en consensuar algunas premisas básicas sobre un acuerdo \\
& preliminar. \\
\hline & Tema marítimo: Las delegaciones subrayaron el proceso de diálogo y darle continuidad \\
efectiva según enfoques realistas y prácticos. \\
Silala: Se continuó con la preparación del documento sobre el sistema hídrico y se decidió \\
elevarlo a consideración de las respectivas autoridades. \\
Tema marítimo: Las delegaciones procuraron preservar el clima de confianza y arribar a \\
propuestas “concretas, factibles y útiles”.
\end{tabular}


Silala: Frente a la falta de coincidencia de los gobiernos sobre el pre-acuerdo se decidió una nueva reunión del Grupo de Trabajo.

\section{Cuadro I: Reuniones de Consultas Políticas Bolivia-Chile}

Fuente: Elaboración propia en base a las Actas de las reuniones del Mecanismo de Consultas Políticas BoliviaChile.

El 24 de abril de 2013, el gobierno boliviano oficializó su demanda ante la CIJ para dirimir el tema marítimo. En su presentación, Bolivia no se focalizó, como lo había hecho en reiteradas oportunidades, en cuestionar de manera directa el Tratado de Paz y Amistad de 1904. Su estrategia radicó en aludir a eventos bilaterales que transcurrieron a lo largo de los años y que constituirían, según La Paz, cuestiones expectaticias a favor de atender el reclamo boliviano (Quitral Rojas, 2013). Bolivia acudió a La Haya amparándose en el Tratado Americano de Soluciones Pacíficas de 1948 (conocido como Pacto de Bogotá) del cual Chile también es parte. Éste establece en su artículo 31 que las partes contratantes reconocen como obligatoria ipso facto la jurisdicción de la CIJ en las controversias de orden jurídico sobre: la interpretación de un tratado; cualquier cuestión de derecho internacional; la existencia de todo hecho que, si fuere establecido, constituiría la violación de una obligación internacional y la naturaleza o extensión de la reparación que ha de hacerse por el quebrantamiento de una obligación internacional (Tratado Americano de Soluciones Pacíficas, 1948).

En su escrito, Bolivia argumenta que la disputa se refiere a la supuesta obligación de Chile de negociar de buena fe y efectivamente para llegar a un acuerdo que le garantice un acceso soberano al Pacífico. Según el Estado andino -y por ello se apoya en el artículo 31- en numerosos momentos, Chile se comprometió a negociar una salida soberana al mar pero como dicha obligación se ha incumplido, se le reclama el deber de hacerlo (International Court of Justice, 2013). La delegación boliviana identificó en el documento un conjunto de hechos en el transcurso del siglo XX -e incluso con anterioridad a la firma del Tratado de 1904- para respaldar su demanda ante el tribunal. Para Quitral Rojas (2013) de los acontecimientos mencionados, sobresalen las conversaciones entre Bolivia y Chile durante los gobiernos de Gabriel González Videla (1946-1952) y Enrique Hertzog (1947-1949); la Declaración Conjunta de Charaña en 1975 y la Agenda de los Trece Puntos. Para Bolivia, estos eventos, como otros que son parte del documento serían indicadores que Chile se habría comprometido a negociar su condición de mediterraneidad por lo que, ante el incumplimiento, se solicitó la intervención de la CIJ en el asunto.

Frente a los sucesos, la administración Bachelet optó como estrategia cuestionar la competencia del tribunal a través de la presentación de una excepción preliminar el 15 de julio de 2014. Con esta herramienta -contemplada en el reglamento de la CIJ- la delegación chilena estableció un 'impasse' en el tratamiento de la demanda boliviana ya que el tribunal, en base a los alegatos de las partes, debía pronunciarse, en primer lugar, si posee o no competencia para dirimir el litigio. La utilización de la excepción preliminar merece una doble lectura. Por un lado, deja entrever la intención de Chile de mantener la disputa en el ámbito bilateral, tal como se establecía en la Agenda de los Trece Puntos. Por otro lado, da cuenta de la visión del gobierno nacional sobre el asunto. Para Chile, dicha demanda, presentada como un supuesto incumplimiento de una obligación a negociar, está dirigida a revisar y/o modificar el Tratado de 1904 a través del cual los dos Estados acordaron, entre otros puntos, que Bolivia accede al Pacífico mediante el libre derecho de tránsito comercial por territorio chileno (Tratado de Paz y 
Amistad, 1904, art. 6). En la objeción preliminar se afirma que el reclamo de Bolivia queda fuera de la jurisdicción de la CIJ porque el Pacto de Bogotá la excluye de los asuntos ya resueltos con anterioridad a su firma. Agrega que: "(...) the character of Bolivia's access to the Pacific Ocean are matters that were settled by, and remain governed by, the Treaty of Peace and Amity agreed (...) in 1904 (...)" (International Court of Justice, 2014a: 1).

El 7 de noviembre de 2014 Bolivia elevó una presentación escrita en respuesta a la excepción preliminar chilena. En el documento remarcó que el demandado había interpretado de forma errónea el objeto de la controversia. Fue Chile, que en reiteradas ocasiones, afirmó su voluntad de negociación, independientemente del Tratado de 1904. Por ello, el gobierno boliviano se presentó en la CIJ con miras a que ese compromiso fuera cumplido de buena fe (International Court of Justice, 2014b: 9).

Desde el 4 al 8 de mayo de 2015, las delegaciones de Bolivia y Chile expusieron sus alegatos orales para defender sus respectivas posiciones. El 24 de septiembre del mismo año, la CIJ dictaminó que posee competencia para proceder sobre la demanda boliviana por 14 votos a favor y 2 en contra en base a los artículos XXXI y VI del Pacto de Bogotá. Según el fallo del organismo, la obligación por parte de Chile de negociar con Bolivia un acceso soberano al Pacífico no forma parte de manera expresa o implícita de las disposiciones del Tratado de 1904 (International Court of Justice, 2015: 19). De este modo, al no haber sido resuelta por las partes, el tribunal se declaró competente para actuar en el litigio, aunque sin capacidad para intervenir en el contenido o resultado de la negociación en caso de constatar el incumplimiento por parte de Chile (International Court of Justice, 2015: 14).

Los representantes de ambos Estados tienen aún un arduo camino por recorrer puesto que fueron autorizados por el tribunal para presentar en el transcurso de 2017 una réplica y una dúplica, respectivamente. Las audiencias orales están previstas para finales del presente año o el siguiente, según trascendidos de las delegaciones ante la CIJ.

La imposibilidad del diálogo directo entre La Paz y Santiago se reflejó en otro asunto sensible de la agenda: la cuestión del Silala; sistema hídrico que alimenta de agua a poblaciones de la Región de Antofagasta y a las actividades mineras de la zona. En su discurso conmemorativo al día del mar, el 23 de marzo de 2016, Evo Morales acusó a su vecino de utilizar las aguas del Silala de manera arbitraria y sin compensación alguna. Asimismo, planteó la posibilidad que este asunto fuera judicializado ya que, como la demanda marítima, no tuvo avances en el marco de la Agenda de los Trece Puntos (Morales, 2016).

A lo largo del siglo XX, el aprovechamiento del Silala formó parte de la relación bilateral sin presentarse inconvenientes en torno al mismo. Los primeros antecedentes se remontan a 1906 y 1908 cuando Chile otorgó una concesión sobre el recurso hídrico a la empresa Ferrocarril de Antofagasta a Bolivia (FCAB) y Bolivia hizo lo propio dos años más tarde (Neira, 2016). Hacia fines de la década del noventa, el gobierno boliviano a través de la prefectura de Potosí revocó la concesión otorgada a FCAB y en abril del año 2000 se la adjudicó a la empresa DUCTEC la cual tendría derecho al uso y aprovechamiento del Silala para fines de comercialización y/o exportación por un período de 40 años. Debido a su condición de adjudicataria, DUCTEC le reclamó a FCAB y a la Corporación Nacional del Cobre de Chile (Codelco) una indemnización 
por la utilización de las aguas. Chile se negó a escuchar este reclamo ya que la solicitud boliviana implicaría, según autoridades nacionales, desconocer el carácter internacional del Silala (Neira, 2016). En palabras de Faundes Sánchez (2007: 385): "la posición oficial chilena considera que el Silala es un río internacional que nace en Bolivia y que fluye naturalmente hacia el territorio nacional (...) aparece en los mapas de Bolivia y Chile, en forma significativa en el mapa adjunto al Tratado de Paz de 1904".

Como se indicó supra, el tratamiento del Silala fue, al igual que el marítimo, uno de los ítems de las reuniones del Mecanismo de Consultas Políticas Bolivia-Chile, mantenidas en el marco de la Agenda de los Trece Puntos. En agosto de 2009 los dos Estados firmaron un preacuerdo en el cual se reconocía que "la preservación, sostenibilidad, uso y aprovechamiento del sistema hídrico del Silala [sería] en beneficio de ambos países (Llanos Mansilla, 2013: 357). Finalmente, el pre-acuerdo no prosperó.

La posibilidad de encontrarse con un nuevo diferendo ante La Haya, impulsó la judicialización del conflicto por parte de la administración Bachelet. El 6 de junio de 2016, Chile elevó una demanda contra Bolivia ante la CIJ para que ésta se pronuncie sobre la naturaleza del sistema Silala y los derechos y obligaciones correspondientes a las partes. Al igual que Bolivia, Chile, acudió al organismo amparándose en el artículo XXXI del Pacto de Bogotá de 1948. De acuerdo al escrito, el Silala es un curso de agua internacional, cuyo uso debe ser equitativo y razonable, de conformidad con el derecho internacional consuetudinario (International Court of Justice, 2016). En cambio, Bolivia sostiene que el Silala es un manantial y que le corresponden el $100 \%$ del uso de sus aguas. En virtud de lo expuesto, el organismo estableció los tiempos límites para la presentación de la memoria y la contra-memoria (julio de 2017 y julio de 2018).

\section{Los otros temas de la agenda: ¿posibilidades de trabajo compartido?}

Al realizar un breve repaso por los acuerdos y/o convenidos firmados entre los dos Estados a partir del regreso de la democracia en Chile con el gobierno de Patricio Aylwin (19901994), se observa que a pesar de la inexistencia de relaciones diplomáticas y la presencia 'avasallante' que tiene la cuestión marítima en el vínculo bilateral, los respectivos gobiernos han trabajado en acercar posiciones en otras temáticas que son tradicionales y de mutuo interés entre países que son parte de un contexto contiguo. El siguiente cuadro sintetiza los asuntos que han sido objeto de firma entre la década del noventa y gran parte del presente siglo.

\begin{tabular}{cc}
\hline Año & \multicolumn{1}{c}{ Materias reguladas } \\
\hline $\mathbf{1 9 9 2}$ & $\begin{array}{c}\text { Acuerdo sobre Control, Fiscalización y Represión del Tráfico Ilícito de Estupefacientes y Sustancias } \\
\text { Psicotrópicas y Productos Químicos Esenciales y Precursores. }\end{array}$ \\
\hline $\mathbf{1 9 9 3}$ & $\begin{array}{c}\text { Acuerdo Chile-Bolivia sobre Facilidades para los Trabajos que Yacimientos Petrolíferos Fiscales } \\
\text { Bolivianos realiza en su Terminal de Arica }\end{array}$ \\
\hline $\mathbf{1 9 9 3}$ & Acuerdo de Transporte Aéreo Internacional. \\
\hline $\mathbf{1 9 9 3}$ & Acuerdo de Complementación Económica (ACE 22) y Protocolos adicionales ${ }^{1}$ \\
\hline
\end{tabular}

\footnotetext{
${ }^{1} 1^{\circ}$ Protocolo: Incorpora el acuerdo de cooperación turística (1994); $2^{\circ}$ Protocolo: Sustituye los anexos de preferencias (1994); $3^{\circ}$ Protocolo: Coordinación y cooperación técnica en materia de cuarentena agrícola y forestal (1994); $4^{\circ}$ Protocolo: Marco jurídico sobre promoción y protección recíproca de inversiones (1994); $5^{\circ}$ Protocolo: Convenio para acciones específicas de cooperación comercial (1994); $6^{\circ}$ Protocolo: Cooperación técnica y científica (1995); $7^{\circ}$ Protocolo: Ampliación del programa de liberación (1997); $8^{\circ}$ Protocolo: Cooperación y coordinación en materia de sanidad silvoagropecuaria (1997); $9^{\circ}$ Protocolo: Medidas relativas a normalización (1997); $10^{\circ}$ Protocolo: Ampliación del programa de liberación (1998); $11^{\circ}$ Protocolo: Disposición relativa a la no
} 
1995 Acuerdo sobre Exención del Requisito de Visa para los Titulares de Pasaportes Diplomáticos, Oficiales, Especiales y de Servicio (*)

1997 Creación del Comité de Frontera Chile-Bolivia. Comprende las Regiones chilenas I de Tarapacá y II de Antofagasta y los Departamentos de La Paz, Oruro y Potosí de Bolivia. Abarca también los pasos fronterizos habilitados y sus correspondientes áreas geográficas.

\begin{tabular}{cc}
\hline $\mathbf{1 9 9 9}$ & Acuerdo sobre Reconocimiento Recíproco de Licencias de Conducir. \\
\hline $\mathbf{2 0 0 1}$ & Tratado sobre Transferencia de Personas Condenadas. \\
\hline $\mathbf{2 0 0 4}$ & Convenio sobre Controles Integrados de Frontera. \\
\hline $\mathbf{2 0 0 7}$ & $\begin{array}{c}\text { Acuerdo sobre el establecimiento de un Grupo de Trabajo para que Analice y Considere Proyectos de } \\
\text { Interés Mutuo que se Enmarquen en los Programas de Lucha Contra la Pobreza. }\end{array}$ \\
$\mathbf{2 0 0 8}$ & $\begin{array}{c}\text { Habilitación del puerto de Iquique para el libre tránsito a favor de Bolivia, conforme a las normas del } \\
\text { Tratado de Paz, Amistad y Comercio de } 1904 \text { y se refiere a la constitución de una agencia aduanera } \\
\text { boliviana en ese lugar. }\end{array}$ \\
\hline $\mathbf{2 0 0 8}$ & Acuerdo para la Cooperación entre Carabineros de Chile y la Policía Nacional de Bolivia. \\
\hline
\end{tabular}
Cuadro II: Instrumentos jurídicos bilaterales Chile-Bolivia

(*)Derogado en febrero de 2017.

Elaboración propia según datos de ALADI y la Biblioteca del Congreso Nacional de Chile.

De las materias indicadas con anterioridad, en este trabajo, se destacan tres áreas puntuales que son constitutivas de la lógica relacional entre estos dos vecinos: el aspecto económico-comercial; la permanencia de la cooperación técnica horizontal y la dinámica transfronteriza entre el norte chileno y el sur y sudoeste boliviano. Sin desconocer que el tratamiento conjunto por parte de ambas Cancillerías debe continuar profundizándose, en estas líneas, se invita a reflexionar desde una mirada propositiva sobre las potencialidades de estas temáticas con miras a contribuir al mejoramiento y diversificación del vínculo. En esta dirección, la primera mandataria, Michelle Bachelet, y el Ministro de Relaciones Exteriores de Chile, Heraldo Muñoz, han sostenido en diversas oportunidades la necesidad de separar las disputas que los dos Estados mantienen en CIJ del resto de los temas que integran la agenda bilateral (América Economía, 2014; Vargas, 2016).

\section{La dimensión económico-comercial}

Las relaciones económicas y comerciales entre Chile y Bolivia se inscriben y a su vez, se encuentran reguladas por el Acuerdo de Complementación Económica (ACE) 22, firmado el 6 de abril de 1993, el cual se enmarca en el proceso de integración del Tratado de Montevideo de 1980 (DIRECON, 2008: 4). Dicho documento fijó los siguientes objetivos: 1- el logro de una creciente y progresiva integración de las economías estatales; 2- la ampliación del intercambio comercial de bienes y servicios y de las inversiones recíprocas; 3 - el avance armónico y equilibrado del comercio binacional; 4-el fomento de la cooperación económica en áreas de interés bilateral y 5- la promoción de la participación de los agentes económicos privados (ACE 22, 1993, art. 1). Desde su puesta en vigencia -conjuntamente con los protocolos adicionales que

aplicación de cláusulas de salvaguardia, en determinadas condiciones (2000); 12 Protocolo: Modificación de las condiciones de acceso al mercado chileno, hasta el 31 de diciembre de 2002 (2001); 13 ${ }^{\circ}$ Protocolo: Prorroga desde el 01/01/2003 hasta el $31 / 12 / 2003$, las condiciones de acceso al mercado chileno, convenidos al amparo del $12^{\circ}$ Protocolo adicional (2002); $14^{\circ}$ Protocolo: Incorporación del Acuerdo de Cooperación e Intercambio de Información en materia aduanera entre la República de Chile y la República de Bolivia (2004);15 Protocolo: Ampliación y profundización del programa de liberación del Acuerdo, para cuyo fin Chile otorgará el cien por ciento $(100 \%)$ de preferencia arancelaria a las importaciones de cualquier producto originario de Bolivia, excepto aquellos contenidos en el Anexo del presente Protocolo (2006); 16º Protocolo: Incorporación del Acuerdo de Cooperación suscrito entre la Dirección General de Relaciones Económicas Internacionales (PROCHILE) y el Centro de Promoción Bolivia (CEPROBOL) (2006). 
se firmaron a lo largo del tiempo- se fue extendiendo el universo de productos que gozan de preferencias arancelarias. Según la Aduana Nacional de Bolivia, las preferencias otorgadas por Chile abarcan, a partir del $10^{\circ}$ Protocolo Adicional (1998), casi la totalidad de productos con el beneficio del $100 \%$ a favor de Bolivia, a excepción de productos de la carne, azúcar y harina. Con respecto a Bolivia, se decidió una preferencia del 100\% para 292 productos, 98 con reciprocidad y 194 sin reciprocidad; una preferencia del 50\% para 15 productos, 1 con reciprocidad y una preferencia del $30 \%$ para 1 producto, con 1 reciprocidad. $^{2}$

Al momento de evaluar las implicancias del ACE 22 en el intercambio comercial boliviano-chileno desde su puesta en marcha, se presentan diferentes connotaciones. Desde una óptica estrictamente general, ni Bolivia ni Chile se posicionan mutuamente como mercados prioritarios para sus respectivas exportaciones. Tomando en consideración el porcentaje que cada país representa en el valor total de sus ventas al exterior, las estadísticas ofrecidas por la Asociación Latinoamericana de Integración (ALADI) dan cuenta que, para Bolivia, Chile ha oscilado entre los puestos 12 y 14 como destino de ventas, mientras que el Estado andino ha hecho lo propio entre los puestos 24 y 26 en las exportaciones chilenas. ${ }^{3}$ El cuadro III ejemplifica la evolución de los porcentajes -en términos de participación de las ventas sobre el total exportado- en la relación bilateral.

\begin{tabular}{crrrrrrrrrrrrr}
\hline Exportacion & $\mathbf{2 0}$ & $\mathbf{2 0}$ & $\mathbf{2 0}$ & $\mathbf{2 0}$ & $\mathbf{2 0}$ & $\mathbf{2 0}$ & $\mathbf{2 0}$ & $\mathbf{2 0}$ & $\mathbf{2 0}$ & $\mathbf{2 0}$ & $\mathbf{2 0}$ & $\mathbf{2 0}$ & $\mathbf{2 0}$ \\
es & $\mathbf{0 3}$ & $\mathbf{0 4}$ & $\mathbf{0 5}$ & $\mathbf{0 6}$ & $\mathbf{0 7}$ & $\mathbf{0 8}$ & $\mathbf{0 9}$ & $\mathbf{1 0}$ & $\mathbf{1 1}$ & $\mathbf{1 2}$ & $\mathbf{1 3}$ & $\mathbf{1 4}$ & $\mathbf{1 5}$ \\
\hline de Bolivia a & 2,6 & 2,2 & 1,2 & 1,6 & 1,2 & 1,2 & 1,5 & 1,4 & 1,7 & 1,9 & 1,3 & 0,8 & 1,0 \\
Chile & 4 & 2 & 9 & 1 & 2 & 3 & 3 & 3 & 1 & 8 & & 7 & 2 \\
\hline de Chile a & 0,6 & 0,4 & 0,5 & 0,5 & 0,4 & 0,6 & 0,6 & 0,4 & 0,4 & 0,6 & 0,6 & 0,7 & 0,7 \\
Bolivia & 8 & 5 & 5 & 1 & 6 & & 2 & 6 & 7 & & 7 & 2 & 1 \\
\hline
\end{tabular}

Cuadro III: Participación (en porcentaje) de las exportaciones totales -según principales socios comercialesFuente: Elaboración propia en base a los datos de ALADI.

Ahora bien, al analizar el intercambio comercial en lo que respecta a su composición, el panorama es más alentador. En otras palabras, son las características propias del intercambio las que resaltan la potencialidad de la dimensión económico-comercial en la agenda bolivianochilena. No debe dejarse de lado que independientemente de las diferencias estructurales entre las dos economías, éstas comparten un patrón de inserción internacional condicionado por la dependencia de las exportaciones del sector primario; hidrocarburos en el caso de Bolivia y minerales, especialmente cobre, en el caso de Chile. A modo de ejemplo, en el quinquenio 20102015, el petróleo, el gas natural (y derivados) y los minerales representaron entre el $79 \%$ y el $82 \%$ de la canasta exportadora boliviana. En Chile, el porcentaje es relativamente menor pero no por ello menos importante. Las exportaciones del sector minero fluctuaron entre el $62 \%$ y el $54 \%$ del total de los bienes vendidos a diferentes destinos.

En el marco del ACE 22, Bolivia exporta a Chile productos del rubro 'no tradicional', entre los cuales se encuentran insumos y bienes intermedios como bebidas, tortas de soya, líquidos alcohólicos y vinagre, cerveza de malta, piedras preciosas y semipreciosas, maderas,

\footnotetext{
${ }^{2}$ Consultar el sitio electrónico de la Aduana Nacional de Bolivia. Acuerdo de Complementación Económica N² 22 Bolivia-Chile. Recuperado de: http://www.aduana.gob.bo/aduana7/content/acuerdo-de-complementaci\%C3\%B3n-econ\%C3\%B3mican\%C2\%BA-22-bolivia-\%E2\%80\%93-chile

3 Consultar el sistema de información de comercio exterior de ALADI. Recuperado de: http://consultawebv2.aladi.org/sicoexV2/jsf/comercio_exterior_item_arancelario.seam
} 
artesanías, etc. (IBCE, 2015). En el período 2003-2015, el mercado chileno se ha mantenido entre el $4^{\circ}$ y $5^{\circ}$ lugar como destino de los productos no tradicionales en América Latina y el Caribe. ${ }^{4}$ En este sentido, Chile, al igual que otros importadores de productos no tradicionales (Colombia, Perú, Venezuela, Argentina y Estados Unidos, entre otros), es una buena opción para fortalecer la diversificación de una economía que, como ya se indicó, depende de un rubro volátil como es el extractivo.

En el caso de Chile, sus exportaciones hacia Bolivia son principalmente del sector industrial -aceites comestibles destilados, manufacturas de pasta celulosa, preparaciones alimenticias, productos farmacéuticos, plásticos, preparaciones de perfumería, fibras sintéticas, etc.- (IBCE, 2015). La Dirección General de Relaciones Económicas Internacionales de Chile (DIRECON) remarca que la composición de las exportaciones hacia su vecino le otorga un carácter diferenciador al comercio bilateral. A diferencia de las exportaciones tradicionales de Chile, las ventas hacia Bolivia son bienes de valor agregado que contribuyen a ampliar la oferta exportadora del país (DIRECON, 2008: 13). ${ }^{5}$ El organismo agrega que si bien Bolivia no es uno de los principales socios, "la estructura [de ventas] se ha mantenido relativamente estable en los últimos años" y con saldos favorables para Chile debido a los rasgos de los productos exportables (DIRECON, 2008: 8).

Otro dato positivo que deriva del ACE 22 radica en que el proceso de rebaja arancelaria ha impulsado la participación de nuevas empresas en el mercado boliviano. En esta dirección, Castañeda (2015: 11) señala que las cifras comerciales son "discretas" pero benefician a pequeños y medianos empresarios del norte del país, "representando la zona franca un $70 \%$ de los envíos". Finalmente, se destaca que la dinámica comercial en el marco del ACE 22 ha movilizado inversiones, en particular, de origen chileno que no estuvieron ajenas a los altibajos. Los montos no son significativos, con picos de USD 27.1 millones en 1996 y USD 26.9 millones en $2009^{6}$, aunque su aspecto más notable se relaciona con su capacidad de generar empleo en el país receptor. Entre 1990 y 2015, la inversión chilena en Bolivia se trasladó en la creación del $1.7 \%$ del empleo directo y el $0.5 \%$ del empleo indirecto. Estos datos ubican a Bolivia en el $8^{\circ}$ lugar dentro de los 21 destinos estudiados en la temática (DIRECON, 2016: 25).

\section{Cooperación técnica bilateral}

De acuerdo con Colacrai (2013: 161) "las políticas de cooperación internacional que llevan adelante los Estados son una parte integrante de su política exterior y, en gran medida, reflejan los principios y valores que la sustentan [y] dan cuenta de su posicionamiento internacional". Siguiendo con la autora, en el caso de Chile, 'la obligación a cooperar' fue incorporada en el diseño de la política exterior de los años noventa, conectándose así con el valor de lo ético, el respeto del derecho internacional pero también el pragmatismo y la inserción internacional (2013: 165).

\footnotetext{
4 Consultar los boletines estadísticos del sector externo del Banco Central de Bolivia (BCB). Recuperado de: https://www.bcb.gob.bo/?q=pub_boletin-sector-externo

${ }_{5}^{5}$ Por otro lado, se recomienda consultar el trabajo de Ross \& Leiva (2017), quienes analizan la dimensión comercial bilateral desde otra perspectiva.

${ }^{6}$ Datos del BCB.
} 
En términos generales, Chile es catalogado como un país de renta media alta (PRMA) ${ }^{7}$; situación que lo ubica en una doble dimensión: como receptor de cooperación en áreas que son deficitarias y como oferente en aquellas materias que tienen un mayor grado de solidez. La política de cooperación se canaliza a través de la Agencia Chilena de Cooperación Internacional para el Desarrollo (AGCID), anteriormente AGCI, creada en 1990 como un organismo descentralizado, encargado de captar y gestionar los recursos de la cooperación internacional. Desde su creación se fue consolidando en brindar cooperación técnica entre países en desarrollo -cooperación sur-sur- mediante el intercambio de experiencias, tecnologías y formación de recursos humanos entre países de igual o menor crecimiento relativo. También participa de manera activa en diversos esquemas de cooperación triangular.

Bolivia, en cambio, es entendida como un país de renta media baja (PRMB) y en consecuencia, uno de los principales destinos de cooperación en el contexto sudamericano, incluyendo la chilena. En el marco del ACE 22, la suscripción del Sexto Protocolo Adicional en 1995 estableció un punto de inflexión sobre la cooperación técnica y científica entre los dos Estados al fijar un marco jurídico para regular la cuestión (AGCI, 1995). Durante los años noventa, se llevaron a cabo actividades conjuntas para identificar convergencia de intereses. Como resultado, ambos Estados acordaron trabajar en materia de pobreza, modernización del Estado, fortalecimiento institucional, comercio de pymes y marketing, entre otros. El distanciamiento político entre los dos países no ha sido un obstáculo para que la AGCID y su contraparte boliviana, en particular, el Viceministerio de Inversión Pública y Financiamiento Externo, desarrollaran acciones y proyectos de cooperación técnica en dos grandes áreas: la social (salud y educación) y la económica (infraestructura, servicios y sectores productivos). ${ }^{8} \mathrm{El}$ otorgamiento de becas para estudios de grado y posgrado es otra de las modalidades de cooperación bilateral por parte de Chile en Bolivia.

¿Qué resultados pueden observarse a lo largo de estos años? De acuerdo con la información proporcionada por la AGCID y la Secretaría General Iberoamericana (SEGIB), se desprende que los proyectos y las actividades de cooperación chilenos en Bolivia han tenido continuidad aún ante la falta de superación de la disputa en torno a la cuestión marítima y más recientemente, por las aguas del Silala. "La agenda histórica [empañó] las posibilidades de avanzar hacia soluciones definitivas en cuestiones de soberanía. Pero las puertas (...) de las acciones de cooperación en diversas áreas, no estuvieron cerradas" (Colacrai, 2013: 164-165). De los informes anuales de la AGCID y SEGIB se infiere que en el período 2006-2014 Chile participó como oferente en 88 acciones y proyectos de cooperación destinados a satisfacer necesidades en Bolivia en educación, salud, pobreza, fortalecimiento institucional, servicios productivos e infraestructura.

Entre 2006 y 2014, Bolivia fue uno de los principales receptores de la cooperación técnica chilena, ubicándose conjuntamente con Argentina, México y Venezuela, entre otros,

\footnotetext{
${ }^{7}$ Uno de los principales criterios utilizados por el Banco Mundial (BM) para clasificar las economías estatales es el ingreso nacional bruto (INB) per cápita anual. Frente a este reduccionismo, el grupo de PRM es muy amplio y heterogéneo al comprender países cuyos INB per cápita va de USD 1.026 a USD 12.475 (según la clasificación al 1 de julio de 2016). Al interior de este grupo se produce una distinción entre los PRM baja (USD 1026 a USD 4035) y los PRM alta (USD 4036 a USD 12475). Según el BM, al 2015, Chile sería un país de ingreso alto (USD. 14.100 INB per cápita). No obstante, ha sido el gobierno chileno el encargado de reclamar la necesidad de continuar recibiendo cooperación de los países más desarrollados.

${ }^{8}$ Consultar los informes anuales de cooperación sur-sur y triangular de la SEGIB. Recuperado de: http://segib.org/
} 
como uno de los actores más activos en materia de cooperación en el país andino. ${ }^{9}$ En este sentido, la Agenda de los Trece fue clave para trabajar en base a intereses y objetivos compartidos. De los proyectos y acciones implementadas, se señalan como las más relevantes el programa de hermanamiento entre los hospitales Exequiel González Cortés (Santiago) y el Hospital del Niño Dr. Ovidio Aliaga (La Paz) -incorporación de nuevos procedimientos médicos, tecnologías, rediseño de protocolos y donación de equipos-; el fortalecimiento competitivo en materia fitozoosanitaria; la capacitación docente y médica en diversas especialidades y formación de recursos humanos dictados por universidades chilenas acreditadas. $^{10}$

\section{Los contactos transfronterizos}

La dinámica migratoria entre el denominado 'Norte Grande' de Chile -Arica y Parinacota, Tarapacá y Antofagasta- y el sur y sudoeste de Bolivia constituye un aspecto importante en el vínculo bilateral debido a la intensidad de los procesos de movilidad poblacional y a los intercambios de mercancías. En palabras de García Pinzón (2015) dicha área geográfica representa una frontera dual: interna, caracterizada por la marginalidad y la exclusión con respecto a los centros de poder nacional y, externa, frente a los Estados vecinos pero que en la práctica exhibe un gran dinamismo socio-económico propio más allá de los límites políticoadministrativos. Para Ovando Santana \& Ramos Rodríguez (2016: 19) "los habitantes transfronterizos, conscientes del abandono y de sus necesidades, cruzan la frontera de manera constante y construyen una realidad en virtud de las oportunidades que se les manifiestan a uno y otro lado".

En el vínculo con Bolivia, dicha región posee una connotación especial. El Departamento de Extranjería y Migración de Chile sostiene que, en términos comparados con otras comunidades, la boliviana tiene rasgos únicos a nivel de distribución geográfica ya que las zonas con frontera conjunta congregan el $74.6 \%$ de los bolivianos presentes en el país, según el censo de población realizado en 2014 (Departamento de Extranjería y Migración de Chile, 2016: 147). En el período 2005-2014, la migración boliviana en Chile creció 188\% -de 12.505 a 36.036 personas-, representando el $8.8 \%$ del total de migrantes, es decir, la tercera comunidad de extranjeros, después de la peruana y la argentina (Departamento de Extranjería y Migración de Chile, 2016: 23).

El crecimiento migratorio se explica, en gran medida, en la búsqueda de oportunidades laborales en sectores como la agricultura, el comercio, la construcción, y el servicio doméstico. A esto debe agregarse que la comunidad boliviana es "marcadamente joven", en un rango etario de 20 a 35 años, quienes concentran el 50.9\% del total de los migrantes. Otros datos que se observan al interior de esta comunidad y que reafirma su incremento entre 2005 y 2014 son (Departamento de Extranjería Migración de Chile, 2016: 148-149):

Permisos de permanencia definitiva: de 553 a 7.623.

Visas temporarias: 653 a 27.167.

\footnotetext{
${ }^{9}$ Considerando el total de las acciones y proyectos de cooperación por año, Chile se ubicó, en términos generales, como segundo o tercer oferente de cooperación bilateral.

${ }^{10}$ Consultar los balances anuales de cooperación de la AGCID. Recuperado de: https://www.agci.cl/index.php/acerca-deagci/balance-de-gestion-integral
} 
Frente a este cuadro de situación, es menester reivindicar las actividades que lleva adelante el Comité de Frontera Chile-Bolivia, creado en marzo de 1997. Éste comprende las regiones I de Tarapacá y la II de Antofagasta y los departamentos bolivianos de La Paz, Oruro y Potosí. La Dirección Nacional de Fronteras y Límites del Estado (DIFROL) del Ministerio de Relaciones Exteriores de Chile sostiene que su objeto es "promover la facilitación y coordinación fronteriza mediante la formulación de recomendaciones para la adopción de medidas que agilicen el movimiento de personas, vehículos y mercaderías a través de la frontera común, así como proyectos de desarrollo fronterizo". ${ }^{11}$

En las reuniones anuales, los representantes de ambos Estados fueron conviniendo pautas de acción para hacer frente a cuestiones comerciales, tránsito fronterizo, políticas migratorias, sanitarias y aduaneras, turismo, medio ambiente y seguridad. Para ello, la promoción de la cooperación se establece como un eje rector en los contactos entre los dos países ya que la región, si bien, no se encuentra totalmente ajena a las disputas nacionales, necesita del establecimiento de medidas en común para tratar de manera eficiente la cotidianeidad. Del análisis de Valenciano (1990) sobre los comités de frontera, se sintetiza la importancia de estos organismos en base a los siguientes aspectos: 1) son "mecanismos de organización y de funcionamiento simple"; 2) son de gran utilidad en el proceso de facilitación de la relación fronteriza donde el propio contexto se caracteriza por la movilidad de bienes y personas y las problemáticas que ello acarrea y 3) son instancias que permiten potenciar el desarrollo regional y aprovechar las complementariedades de la zona. Además, pueden ser entendidos como una herramienta que les da visibilidad a regiones que no suelen tener un lugar destacado en los lineamientos de las políticas públicas nacionales.

\section{Conclusiones}

El recorrido realizado permite reafirmar el peso que han tenido en la relación bilateral los asuntos donde ambos Estados reivindican derechos propios sobre cuestiones entendidas como 'sensibles' y que retrotraen a un pasado conflictivo, como son la demanda marítima y más recientemente las aguas del Silala. A pesar de la existencia de un breve período de acercamiento, en especial, con la Agenda de los Trece Puntos, la inmovilidad de las posiciones ha sido determinante en la construcción de un vínculo basado en la desconfianza y la animosidad. Esta situación ha generado el sostenimiento a lo largo del tiempo de una rivalidad constante que al ser reproducida por actores diversos -gobiernos, medios de comunicación, sector académico, etc.ha conformado una agenda compartida cuyas temáticas de mayor visibilidad son aquellas que en la actualidad se dirimen ante la CIJ.

Sin desconocer que La Haya es un medio para la solución pacíficas de controversias, la judicialización del tema marítimo y el Silala evidencia la falta de flexibilidad de ambas diplomacias para moverse de sus posiciones y centrarse en los intereses compartidos, que es uno de los principios básicos para emprender un proceso de diálogo entre actores que tienen un diferendo. El pronunciamiento de la CIJ podría entenderse como un punto de inflexión -porque sus decisiones son vinculantes- aunque, la otra cara de la moneda evidencia que este

\footnotetext{
${ }^{11}$ Consultar "Comité de Frontera Chile-Bolivia", DIFROL. Recuperado de: http://www.difrol.gob.cl/bolivia/comite-de-fronterachile-bolivia.html
} 
procedimiento le resta espacio para fomentar el debate político interestatal, el cual es fundamental para avanzar hacia los puntos de encuentros. Por ello y, teniendo en cuenta el momento de la relación, el fortalecimiento otros temas que son parte de la agenda, como los aquí tratados y que también son entendidos como tradicionales, podría considerarse como un primer paso para generar gradualmente más instancias de cooperación. Los tres asuntos analizados comercio, cooperación técnica y dinámica migratoria transfronteriza- tienen potencialidad para darle otro matiz a la relación, más positivo, de mayor densidad y diversidad- lo que no implica dejar de lado el intento por resolver las disputas que encapsulan la vinculación en el pasado.

\section{Bibliografía}

ACE 22 Bolivia-Chile (1993). Aduana Nacional del Estado Plurinacional de Bolivia. Recuperado de: http://www.aduana.gob.bo/aduana7/content/acuerdo-de-complementaci\%C3\%B3necon\%C3\%B3mica-n\%C2\%BA-22-bolivia-\%E2\%80\%93-chile

AGCI (1995). Memoria 1995, Santiago de Chile.

América Economía (2014). Heraldo Muñoz, ministro de RR.EE. de Chile: "una cosa es La Haya y otra el comercio con Bolivia", 15 de octubre.

Castañeda, F. (2015). Chile y Bolivia: una relación compleja pero con futuro, Le Monde diplomatique, junio, 11.

Colacrai, M. (2013). Chile en el contexto de la Cooperación Internacional al Desarrollo ¿varias identidades, diversidad de circuitos y modalidades de acción?, en Miryam Colacrai (comp.) La cooperación internacional desde la visión de los PRM: discusiones conceptuales, diseños de políticas y prácticas sudamericanas, UNR Editora, Rosario, 159-188.

Coloma Rojas, C. (2012). Las relaciones entre Bolivia y Chile tras el anuncio del gobierno boliviano de demandar a Chile ante un tribunal internacional, Revista Política y Estrategia, 119, 131-169.

Correa Vera, L. \& García Pinzón, V. (2012). Aunque las aguas nos dividan: las relaciones chilenobolivianas y la construcción de una agenda común, Revista Latinoamérica, 54, 75-110.

Correa Vera, L. \& García Pinzón, V. (2013). Turbulencias desde el mar: Chile y Bolivia, Revista Sí Somos Americanos, 13(1), 93-121.

Departamento de Extranjería y Migración (2016). Ministerio del Interior y Seguridad Pública de la República de Chile, Santiago de Chile.

DIRECON (2008). Relaciones económicas entre Chile y Bolivia. Evaluación a 15 años del ACE 22, Ministerio de Relaciones Exteriores de la República de Chile.

DIRECON (2016). Presencia de inversiones directas de capitales chilenos en el mundo, 1990diciembre 2015, Ministerio de Relaciones Exteriores de Chile, Santiago de Chile. 
DIREMAR (2014). Tratado de Paz y Amistad suscrito en Santiago el 20 de octubre de 1904, Libro del Mar, Ministerio de Relaciones Exteriores, Estado Plurinacional de Bolivia.

Faundes Sánchez, C. (2007). Las aguas que nos dividen. Causas y mecanismos de resolución de los conflictos por el agua dulce entre Chile y Bolivia, en M. Artaza Rouxel \& P. Milet García (Editores), Nuestros Vecinos, 375-398, Santiago, RIL Editores.

García Pinzón, V. (2015). Estado y frontera en el norte de Chile, Revista Estudios fronterizos, nueva época, 16(31), 117-148.

IBCE (2015). Intercambio comercial Bolivia-Chile, Boletín Bisemanal, 411, La Paz, 7 de mayo.

International Court of Justice (2013). Application Instituting Proceedings. Obligation to negotiate access to the Pacific Ocean (Bolivia $v$. Chile), 24 de abril. Recuperado de: http://www.icjcij.org/docket/files/153/17338.pdf

International Court of Justice (2014a). Obligation to negotiate access to the Pacific Ocean (Bolivia v. Chile). Preliminary Objection of the Republic of Chile, 15 de julio, vol. 1. Recuperado de: http://www.icj-cij.org/docket/files/153/18616.pdf

International Court of Justice (2014b). Obligation to negotiate access to the Pacific Ocean (Bolivia $v$. Chile). Written Statement of the Plurinational State of Bolivia on the Preliminary Objection to jurisdiction filed by Chile, 7 de noviembre. Recuperado de: http://www.icjcij.org/docket/files/153/18622.pdf

International Court of Justice (2015). Obligation to negotiate access to the Pacific Ocean (Bolivia v. Chile). Preliminary Objection, 24 de septiembre. Recuperado de: http://www.icjcij.org/docket/files/153/18746.pdf

International Court of Justice (2016). Chile institutes proceedings against Bolivia with regard to a dispute concerning the status and use of the waters of the Silala, 6 de junio. Recuperado de: http://www.icj-cij.org/docket/files/162/19018.pdf

Lacoste, P. (2015). Enclaustramiento de Bolivia y visión del otro: nueva mirada a los orígenes de la Guerra del Pacífico, Cuadernos de Historia, Universidad de Chile, 43, 109-132.

Llanos Mansilla, H. (2013). El caso del río Silala o Siloli: diferendo chileno-boliviano, Anuario Hispano-Luso-Americano de derecho internacional, (21), 339-365.

Lorenzini, M. E. (2017). Contexto contiguo y operaciones de mantenimiento de la paz en Argentina, Chile y Venezuela: ¿alianzas estratégicas?, Revista Íconos, 58, 225-245.

Morales, E. (2016). Discurso del Presidente del Estado Plurinacional de Bolivia, La Paz, 23 de marzo. 
Neira, J. (2016). Las claves para entender la demanda de Chile contra Bolivia ante La Haya por el río Silala, El Mercurio, 11 de junio.

Ovando Santana, C. \& Ramos Rodríguez, R. (2016). Imaginarios geográficos en torno a la franja fronteriza de Tarapacá: el Estado y los habitantes/migrantes, Revista Scripta Nova, XX (529), 1-25.

Quitral Rojas, M. (2013). Chile y Bolivia, una relación compleja, SIC Noticias. Recuperado de: http://www.sicnoticias.cl/?p=1964

Rosales, G. (2011). Las relaciones chileno-bolivianas durante los gobiernos de la Concertación en Chile, Tesina de la Licenciatura en Relaciones Internacionales, Universidad Nacional de Rosario, Argentina.

Ross, C \& Leiva, S. (2017). La política de Chile hacia Bolivia, 1990-2009. Ni coordinación política, ni cooperación económica, Revista Estudios Políticos, Universidad de Antioquia, $50,17-41$.

Tratado Americano de Soluciones Pacíficas (1948). Recuperado de: http://www.oas.org/es/sla/ddi/tratados_multilaterales_interamericanos_A-

42_soluciones_pacificas_pacto_bogota.asp

Valenciano, E. (1990). Los Comités de Frontera: funcionamiento y experiencia, BID/INTAL, Buenos Aires.

Vargas, F. (2016). Cooperación y solidaridad en el medio de la tensión diplomática: La ayuda que Chile le entrega a Bolivia, El Mercurio, 12 de agosto. 